\title{
How to intervene in the caries process: proximal caries in adolescents and adults-a systematic review and meta-analysis
}

\author{
C.H. Splieth ${ }^{1}$ • P. Kanzow ${ }^{2} \cdot$ A. Wiegand ${ }^{2} \cdot$ J. Schmoeckel ${ }^{1} \cdot$ A. Jablonski-Momeni ${ }^{3}$
}

Received: 29 May 2019 / Accepted: 7 January 2020 / Published online: 18 April 2020

(C) The Author(s) 2020

\begin{abstract}
Objectives For an ORCA/EFCD consensus, this systematic review assessed the question "How to intervene in the caries process in proximal caries in adolescents and adults".

Material and methods Separating between the management of initial and cavitated proximal caries lesions, Medline via PubMed was searched regarding non-operative/non-invasive, minimally/micro-invasive and restorative treatment. First priority was systematic reviews or randomized controlled trials (RCTs), otherwise cohort studies. After extraction of data, the potential risk of bias was estimated depending on the study type, and the emerging evidence for conclusions was graded.

Results Regarding non-invasive/non-operative care (NOC), no systematic reviews or RCTs were found. In cohort studies $(n=12)$ with a low level of evidence, NOC like biofilm management and fluoride was associated with a low proportion and slow speed of progression of initial proximal lesions. Minimally/micro-invasive (MI) treatments such as proximal sealants or resin infiltration (four systematic reviews/meta-analyses) were effective compared with a non-invasive/placebo control at a moderate level of evidence. Data on restorative treatment came with low evidence ( 5 systematic reviews, $13 \mathrm{RCTs}$ ); with the limitation of no direct comparative studies, sample size-weighted mean annual failure rates of class II restorations varied between 1.2 (bulk-fill composite) and 3.8\% (ceramic). Based on one RCT, class II composite restorations may show a higher risk of failure compared with amalgam.

Conclusions Proximal caries lesions can be managed successfully with non-operative, micro-invasive and restorative treatment according to lesion stage and caries activity.

Clinical relevance Proximal caries treatment options like non-operative, micro-invasive and restorative care should be considered individually.
\end{abstract}

Keywords Caries $\cdot$ Proximal $\cdot$ Proximal $\cdot$ Non-operative $\cdot$ Micro-invasive $\cdot$ Minimally invasive $\cdot$ Restoration

Electronic supplementary material The online version of this article (https://doi.org/10.1007/s00784-020-03201-y) contains supplementary material, which is available to authorized users.

\section{C.H. Splieth}

splieth@med.uni-greifswald.de

1 Clinic for Preventive and Paediatric Dentistry, University of Greifswald, Fleischmannstr. 42, 17475 Greifswald, Germany

2 Department of Preventive Dentistry, Periodontology and Cariology, University Medical Center Göttingen, Göttingen, Germany

3 Department of Orthodontics, Dental School, Philipps-University Marburg, Marburg, Germany

\section{Introduction}

Caries is a highly prevalent disease and, therefore, a relevant global burden [1-3], in spite of considerable caries reductions in children and adolescents in many countries [4-6]. From adolescence on, the proportion of proximal caries increases and eventually dominates the decayed filled surfaces (DFS) score [7].

A range of treatment options for managing proximal lesions are available, including non-operative/non-invasive and minimally/micro-invasive approaches as well as restorative treatments $[8,9]$. Different terms for caries management options have been used in the literature in the past and suggested for future terminology $[10,11]$. Therefore, in this review, a compromise using the terms non-operative/non-invasive as well as minimally/micro-invasive parallel is used to give credit to the original literature and recent terminology. 
Non-invasive treatment tries to reduce the caries activity via biofilm control and fluoride applications. Micro-invasive treatments include proximal sealants and resin infiltration whichbuild a mechanical border against the cariogenic challenge [12-14]. For more advanced lesions, caries on proximal surfaces of permanent teeth mostly require operative treatment to substitute the hard tissue loss. Most studies in this direction assessed the filling material [15], but also the design of various cavity preparations has been discussed [16].

Due to the high prevalence and relevance of proximal caries [17], the aim of this review was to systematically evaluate the current state of knowledge on how to intervene in the caries process with respect to primary proximal caries in permanent teeth in adolescents and adults. This review is part of the basis for three consensus papers of ORCA and EFCD on caries treatment in children, adults and seniors.

\section{Material and methods}

In succession of the international consensus paper on "When to intervene in the caries process" [10], the question arises on how to intervene. Due to the different clinical approaches for non- and cavitated proximal lesions, this systematic review tries to answer the two following PICO questions (participants, interventions, comparisons and outcomes):

1. "How to intervene in the caries process: What is the effect of non- and minimally-invasive treatment in adolescents and adults with proximal initial caries lesions (E1: caries within outer half of enamel; E2: caries within inner half of enamel; EDJ: caries at the enamel-dentin junction) regarding caries progression?"

2. "How to intervene in the caries process: What is the effect of restorative treatment in adolescents and adults with proximal caries defects (well into dentin, cavitation) regarding survival rates (of the restoration)?"

The authors discussed the review protocol a priori. No further registration was performed as the topic was given to the authors by the joined chairs of the ORCA/EFCD consensus workshop on how to intervene in the caries process.

\section{Search strategy}

For the comprehensive search strategy, Medline was searched via PubMed for appropriate papers up to and including March 2019. The used search terms and the full search strategy are shown in Fig. 1. Titles and abstracts were screened to exclude papers not related to the topic. The remaining full-text articles were screened for eligibility and references handsearched for additional sources. Publications on humans in English language were included.
The inclusion criteria were as follows:

- Patients: adolescents and adults, permanent dentition

- Intervention: non-, micro-invasive and restorative treatment of proximal caries lesions

- Outcome: caries or lesion progression (non-, micro-invasive), survival of restoration

- Meta-analyses, systematic reviews and in case of no studies for these high evidence levels also randomized controlled trials (RCTs) and/or cohort studies

The exclusion criteria were as follows:

- Primary teeth, occlusal caries

- Case presentations, case series

- No clinical outcomes reported

- Studies comparing different treatment techniques (e.g. selective vs non-selective carious tissue removal)

- Endodontically treated teeth

As selected, systematic reviews (see below) were based on RCTs on class I/II or load-bearing restorations in posterior permanent teeth in general; it was decided to extract data on class II restorations from the original RCTs, if possible. Furthermore, as the included systematic reviews were published between 2013 and 2018, further recent RCTs on class II restorations were searched in Medline via PubMed. Thus, the same term (Fig. 1) was used to search with the filters "randomized controlled trial" and "published in the last 5 years".

As studies used different outcome measures, categories Charlie/Delta (U.S. Public Health Service) and 4/5 (FDI World Federation criteria) were counted as failure. In case of multiple publications (with different follow-up periods) from the same study, only data from the most recent publication were extracted.

\section{Screening and selection}

The title and abstract lists, containing 117 (non-operative/noninvasive) and 42 hits (micro-/minimally invasive) for PICO 1 and 251 hits for PICO 2, were independently assessed by three authors, respectively. Each of them screened the titles and abstracts of eligible papers regarding non-operative, microinvasive and restorative treatment in proximal caries independently (CS/JS/AJM, AJM/AW/JS, AW/PK/CS). Papers with questionable inclusion were discussed in three telephone conferences among the authors (CS/AJM/AW/JS).

Eligible papers were read in full text by the authors especially for methodology, bias and outcome. Disagreement between the authors was resolved in additional telephone interviews. The papers that fulfilled all of the selection criteria were processed for data extraction (Fig. 1). 


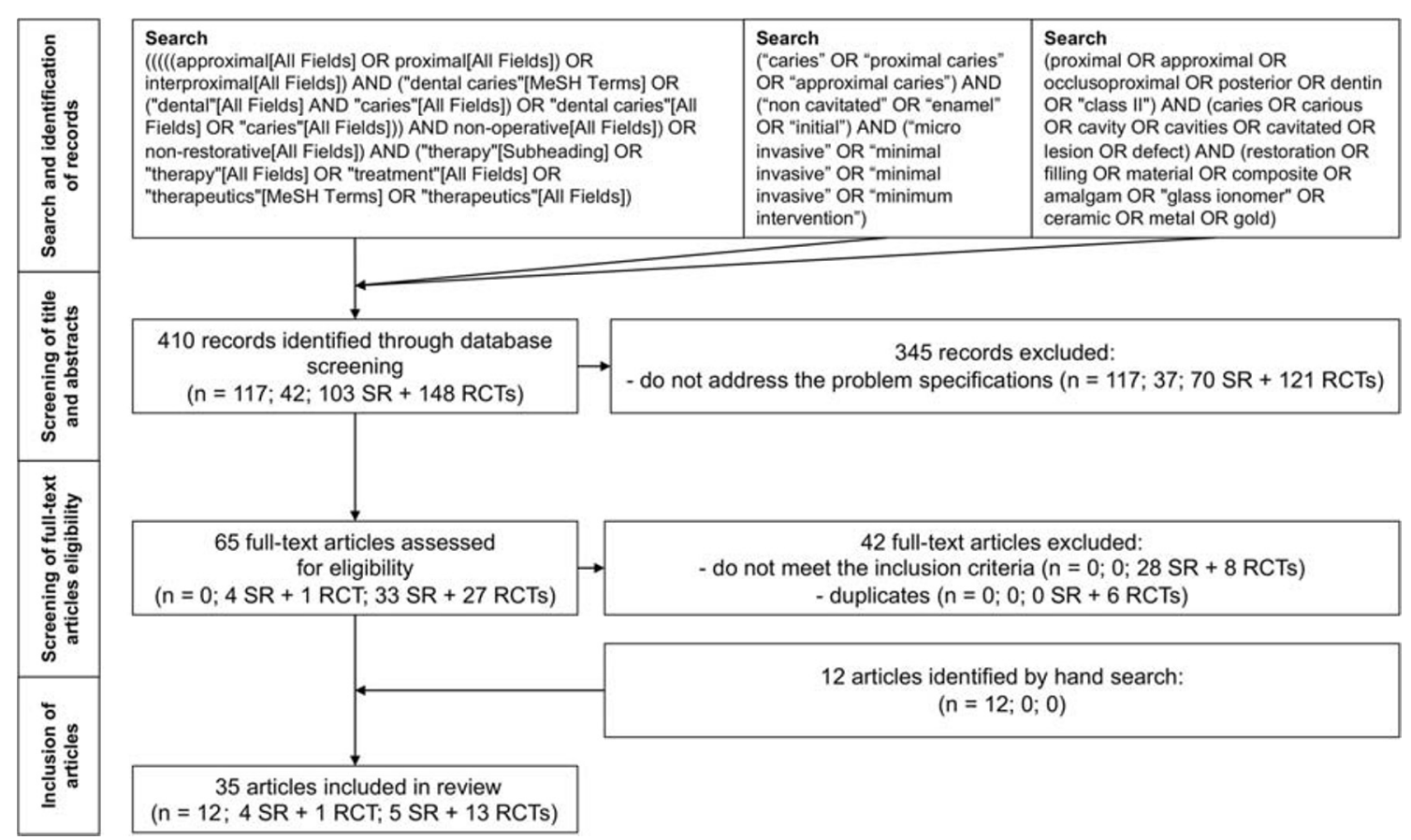

Fig. 1 Flow chart of the systematic review on how to intervene in the caries process in proximal caries in adolescents and adults (n is given separately for studies focussing on non-operative/non-invasive, minimally/micro-invasive, and restorative treatment)

\section{Assessment of heterogeneity}

The heterogeneity across studies was detailed according to the following factors as retrieved by the included literature:

- Study and subject characteristics

- Methodological heterogeneity (variability in study design and risk of bias).

- Analysis performed (descriptive or meta-analysis)

- For PICO 2, a meta-analysis was performed. Hence, Cochrane's $\mathrm{Q}$ and $I^{2}$ statistics were used to assess statistical heterogeneity [18]. Publication bias was evaluated using funnel plots as well as Egger's regression intercept test [19].

\section{Quality assessment}

The reviewer teams (CS/JS, AJM/AW, AW/PK) estimated the risk of bias by scoring the reporting and methodological quality of the included systematic reviews on operative/restorative treatment of proximal caries according to a combination of items described by the PRISMA guideline [20] for reporting systematic reviews and the AMSTAR checklist for assessing the methodological quality of systematic reviews [21].

Risk of bias of RCTs was assessed and classified according to the Cochrane guidelines [22]. For restorative treatment, (1) blinding of participants was not assessed as failure is not an outcome determined by patients, and (2) selective reporting was determined based on missing survival data as only a minority of studies had published protocols available. A list of 27 items adopted from the PRISMA checklist [20] was assessed, and if all individual items were given a positive rating by summing these items, an overall score of $100 \%$ was obtained. Only systematic reviews including meta-analysis could achieve a full score of $100 \%$. The estimated risk of bias was interpreted as follows: $0-40 \%$ may represent a high risk of bias; 40-60\% may represent a substantial risk of bias; 60 $80 \%$ may represent a moderate risk of bias; $80-100 \%$ may present a low risk of bias.

The quality assessment for the non-operative treatment of proximal caries was performed (CS/JS) according to the Newcastle-Ottawa Scale (NOS, Supplement Table 1) for assessing the quality of non-randomized studies [23].

\section{Data extraction}

Information extracted from the studies included publication details, focused question, search results, descriptive or (weighted) mean outcomes and conclusions. Disagreements between the reviewers were resolved by discussion in telephone conferences.

\section{Outcome measures and statistical analysis}

For restorative/operative treatment, the outcome was survival, i.e. restorations not needing any restorative re-intervention (replacement or repair). Random-effects meta-analyses of 
pairwise comparisons between composite and different other restorative materials in class II restorations were performed using Comprehensive Meta-Analysis 3.3.070 (Biostat, NJ, USA). For all restorative materials, annual failure rates (AFRs) and (sample-size weighted) mean annual failure rates (mAFRs) were calculated according to the following formula [24]:

$(1-y)^{z}=1-x$

where $y$ is the mean annual failure rate; $x$ is the failure rate; and $z$ is the number of observation years.

\section{Results}

\section{Non-operative/non-invasive treatment of proximal caries lesions}

As no RCTs and no systematic reviews for non-operative treatment in proximal initial lesions in permanent teeth in adolescents or young adults were retrieved, two other kinds of studies were included (Fig. 1):

1. Longitudinal cohort studies analysing the progression of proximal initial lesions where various measures of nonoperative caries management were administered $(n=4$, Table 1).

2. The control cohort of the RCTs on proximal sealants or infiltrations who also received non-operative caries management for regular home care such as instructions in flossing and fluoride treatment/use for their initial control lesions $(n=8$, Table 2$)$.

This leads to a total of 12 eligible papers (Tables 1 and 2). Already, the oldest study [25] was aiming at alternatives for restorative treatment by evaluating the development of proximal lesions under different fluoride regimes in Swedish and US cohorts. A variety of further studies published the effectiveness of "preventive measures", meaning non-operative/non-invasive treatment on proximal caries lesions in posterior teeth at the beginning of the 1980s [26], but mostly without randomisation or a control group. Still, the feasibility of non-operative measures, especially fluoride varnish, fluoride rinses and fluoridated toothpaste for slowing down the progression of proximal lesions, was demonstrated [27]. Similarly it was stated that the "progression through the inner half of the enamel was slower in the Swedish children than in the U.S. children, perhaps due to greater exposure to topical fluorides in Sweden" [25]. For older Swedish children, progression of the lesions through the outer and inner part of the enamel was much slower than in younger children. Apart from age, the included studies found a clear association of lesion progression with the overall caries risk/activity of the individual. Already in the 1970s, lesions remained confined to for 4-7 years [28], and a series of studies concluded that lesion progression is not inevitably the outcome of initial carious lesions [26].

The longest follow-up of non-invasively managed proximal initial lesions was performed in Sweden with a preference for non-operative caries management [9]. In adolescents and young adults, $46 \%$ of the lesions extended into the inner enamel at baseline did not progress into dentine within a 15year observational period. In contrast, more than $70 \%$ of the proximal caries lesion initially extending to the EDJ progressed into dentin within the first 3 years of adolescents. Lesion progression was considerably lower in premolars $(11 \%)$ than molars $(66 \%)$. Lesion progression is slower in young adults than adolescents: The rate of lesion progression was 2-3 times higher during adolescence ( $12-15$ years of age) than during young adulthood (32.5 vs 10.9/100 surface years) [9].

Thus, even in adolescents, a considerable part of the initial caries lesions does not progress when treated non-operatively, especially in premolars, when limited to the enamel, or in young adults [9], while lesions at the EDJ or in molars as well as adolescents show faster progression.

These findings were confirmed by data on incidence and progression of proximal carious lesions in adolescents in Western Australia [29] which concluded that enamel lesions in proximal surfaces occur relatively rapidly, but the progression into dentine is relatively slow. Clinicians were able to assign the risk of lesion progression, and individuals residing in a water-fluoridated area showed slower lesion progression.

One of the few studies in adults examined Danish soldiers and demonstrated a relatively high progression rate of lesions over 6 years $(57 \%)$ under non-operative care. This group, however, showed a poor compliance to regular flossing/ tooth-stick use (18\%) and also possibly a lower SES and, overall, high caries risk [30]. Non-operative treatment may be less effective in such individuals.

In the studies on proximal sealants or infiltration, nonoperative measures were employed for the control teeth, but to a greatly varying extent, including oral hygiene advice and motivation as well as fluoride application (Table 2). These control groups were included in our assessment of non-operative treatments. In studies from Germany $[11,12,14]$, the vast majority of enamel and even dentin lesions did not progress into a different lesion status within 3 years when treated non-operatively, and even dental subtraction radiography detected that about $60 \%$ of the lesions in young adults remained stable. Even when no improvement of plaque and gingivitis scores was observed over 3 years indicating that oral 


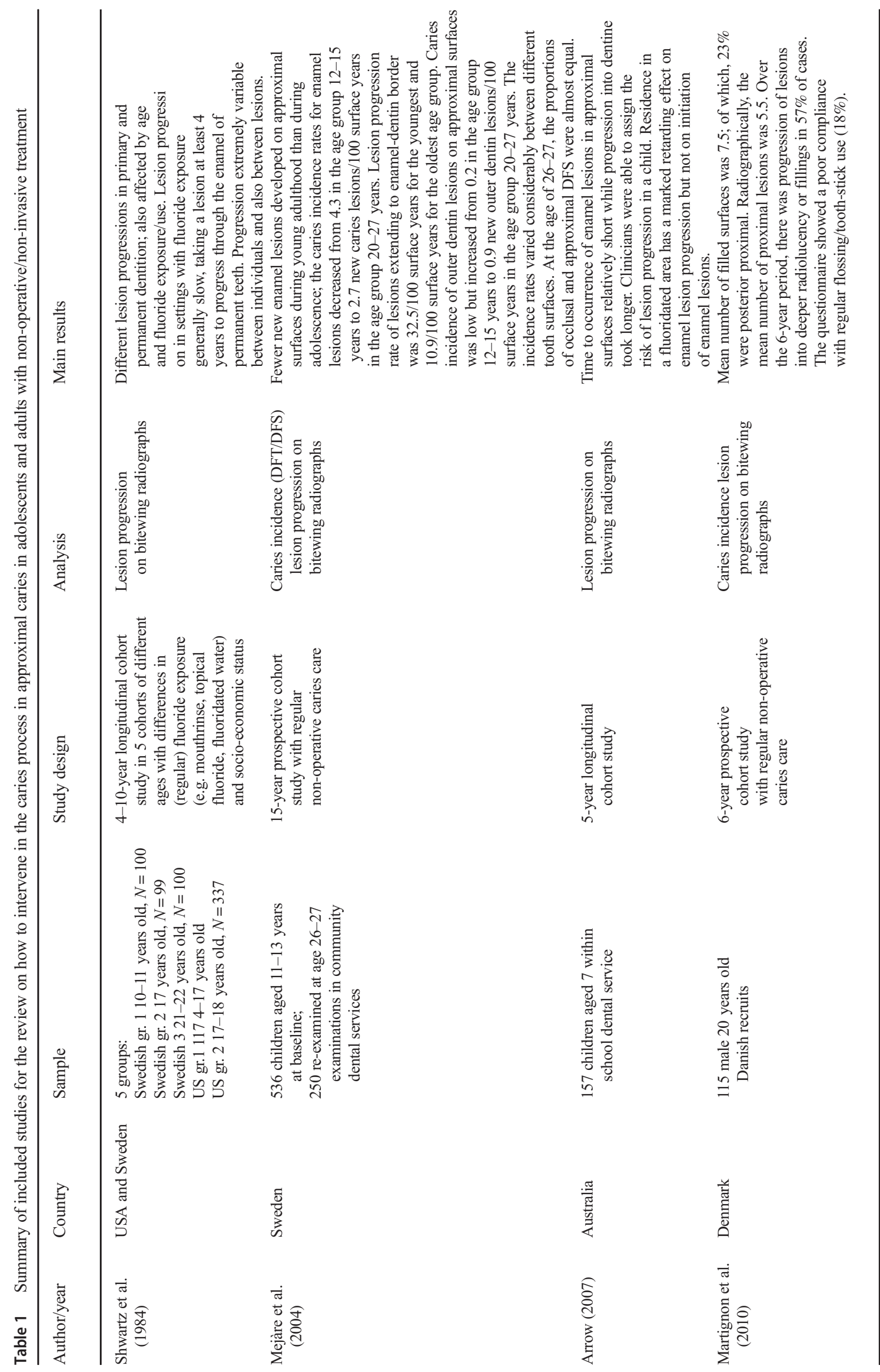


Table 2 Non-operative/non-invasive care provided in RCTs on minimal/micro-invasive caries treatment of proximal lesions in permanent teeth

\begin{tabular}{|c|c|c|c|c|}
\hline Author/year & Study group and design & $\begin{array}{l}\text { Non-operative intervention } \\
\text { (control group) }\end{array}$ & Evaluation system & $\begin{array}{l}\text { Outcome for non-operative } \\
\text { (control group/teeth) }\end{array}$ \\
\hline $\begin{array}{l}\text { Martignon } \\
\text { et al. (2006) }\end{array}$ & $\begin{array}{l}\text { 1.5-year split-mouth RCT on resin } \\
\text { sealing } 15-39 \text { years old, } N=82 \\
\text { Columbia and Denmark }\end{array}$ & $\begin{array}{l}\text { Instruction to floss all the proximal } \\
\text { lesions } 3 \text { times per week }\end{array}$ & $\begin{array}{l}\text { Pairwise analysis and } \\
\text { subtraction radiography }\end{array}$ & $\begin{array}{l}\text { Progression pairwise } 47 \% \\
\text { and with subtraction } \\
\text { radiography } 84 \% \\
\text { progression. Compliance } \\
\text { concerning flossing was } \\
\text { poor }(15 \%) .\end{array}$ \\
\hline $\begin{array}{l}\text { Trairatvorakul } \\
\text { et al. (2011) }\end{array}$ & $\begin{array}{l}\text { 1-year split mouth RCT on sealing } \\
\text { with glass-ionomer cement; } \\
7-19 \text { years old; } N=41 \\
\text { Thailand }\end{array}$ & $\begin{array}{l}\text { Twice daily use of } 1000 \mathrm{ppm} \\
\text { sodium-fluoride dentifrice, tray } \\
\text { application of } 1.23 \% \\
\text { acidulated-phosphate fluoride } \\
\text { gel at baseline and at 6-month } \\
\text { recall; no flossing instructions }\end{array}$ & $\begin{array}{l}\text { Blinded examiner bitewing } \\
\text { radiograph recording of } \\
\text { lesion depths with } \\
\text { software }\end{array}$ & Stable mean lesion depth \\
\hline $\begin{array}{l}\text { Alkilzy } \\
\text { et al. (2011) }\end{array}$ & $\begin{array}{l}\text { 3-year split mouth RCT on sealing } \\
\text { with polyurethane tape; mean } \\
\text { age } 21.3 \pm 5.6 \text { years, } N=50, \\
\text { Germany }\end{array}$ & $\begin{array}{l}\text { Oral home care with dental floss } \\
\text { and fluoridated toothpaste }\end{array}$ & $\begin{array}{l}2 \text { blinded examiners } \\
\text { radiographic bitewing } \\
\text { evaluation (D0-D4) }\end{array}$ & $\begin{array}{l}\text { Only two }(7 \%) \text { of the control } \\
\text { teeth with oral home care } \\
\text { progressed }\end{array}$ \\
\hline $\begin{array}{l}\text { Meyer-Lueckel } \\
\text { et al. (2012), } \\
\text { Paris et al. } \\
\text { (2010) } \\
1.5 \text { year } \\
\text { results }\end{array}$ & $\begin{array}{l}\text { 3-year split-mouth RCT on resin } \\
\text { infiltration, placebo-controlled } \\
\text { young adults }(N=22), 29 \text { pairs } \\
\text { of proximal caries lesions, } \\
\text { Germany }\end{array}$ & $\begin{array}{l}\text { Risk-related instructions for diet, } \\
\text { flossing and fluoridation }\end{array}$ & $\begin{array}{l}\text { Radiographic bitewing } \\
\text { evaluation digital } \\
\text { subtraction radiography } \\
\text { (DSR) and pairwise } \\
\text { comparison (E1-D3) }\end{array}$ & $\begin{array}{l}35 \% \text { progression in pairwise, } \\
42 \% \text { with digital } \\
\text { subtraction radiography }\end{array}$ \\
\hline $\begin{array}{l}\text { Martignon } \\
\text { et al. }(2012)\end{array}$ & $\begin{array}{l}\text { 3-year split-mouth RCT on sealant } \\
\text { vs infiltration adult } \\
\text { students/patients from } \\
\text { Universidad El Bosque } \\
(N=90), \text { Columbia }\end{array}$ & $\begin{array}{l}\text { Placebo treatment (non-invasive } \\
\text { treatment unclear, but likely } \\
\text { regular home care without } \\
\text { specific instructions) }\end{array}$ & $\begin{array}{l}\text { Pair-wise and } \\
\text { digital-subtraction } \\
\text { radiography }\end{array}$ & $\begin{array}{l}74 \% \text { of lesions in outer third } \\
\text { of dentin progressed while } \\
64 \% \text { of lesions around the } \\
\text { EDJ progressed }\end{array}$ \\
\hline $\begin{array}{l}\text { Meyer-Lueckel } \\
\text { et al. (2016) }\end{array}$ & $\begin{array}{l}\text { 1.5-year RCT on resin infiltration, } \\
\text { split mouth in several private } \\
\text { practices high caries risk } \\
\text { children and young adults, } \\
N=87 ; 238 \text { pairs of proximal } \\
\text { caries lesions, Germany }\end{array}$ & $\begin{array}{l}\text { Instructions for a non-cariogenic } \\
\text { diet, flossing and fluoridation, } \\
\text { and individualized non-invasive } \\
\text { interventions }\end{array}$ & $\begin{array}{l}\text { Pairwise comparison of } \\
\text { radiograph evaluated } \\
\text { independently by } 2 \\
\text { blinded evaluators }\end{array}$ & $\begin{array}{l}\text { Progression in } 58 \text { of } 186 \\
\text { control lesions }(31 \%)\end{array}$ \\
\hline $\begin{array}{l}\text { Arthur } \\
\quad \text { et al. (2018) }\end{array}$ & $\begin{array}{l}\text { 3-year split-mouth RCT on } \\
\text { infiltration; high caries risk } \\
\text { participants, } N=22 \text {, Brasil }\end{array}$ & $\begin{array}{l}\text { Placebo infiltration (regular home } \\
\text { care) }\end{array}$ & $\begin{array}{l}\text { Radiographic pair-wise } \\
\text { comparison }\end{array}$ & $\begin{array}{l}5 / 27(18.5 \%) \text { of control } \\
\text { lesions had progressed no } \\
\text { significant additional effect }\end{array}$ \\
\hline $\begin{array}{l}\text { Peters } \\
\quad \text { et al. (2018) }\end{array}$ & $\begin{array}{l}\text { 2-year split-mouth RCT on resin } \\
\text { infiltration + fluoride varnish } \\
\text { high caries risk } 18-23 \text { years } \\
\text { old, } N=42, \text { USA }\end{array}$ & $\begin{array}{l}\text { Mock infiltration (placebo) + } \\
\text { fluoride varnish }\end{array}$ & $\begin{array}{l}\text { Subtraction radiography, } \\
\text { pair-wise comparison, } \\
\text { non-cavitated initial } \\
\text { carious lesions (E2/D1) } \\
\text { patient and evaluators } \\
\text { blinded }\end{array}$ & $\begin{array}{l}\text { Progression rate of } 22 \% \\
\quad(7 / 32) \text { in the control group }\end{array}$ \\
\hline
\end{tabular}

hygiene instructions and motivation may not have been effective [12], only $7 \%$ exhibited a progression in radiographic lesion scores (E1, E2, D1, D2) and $27 \%$ showed a regression, which may, however, be artefactual.

A study on adolescents in Thailand observed a progression for $7 \%$ in non-operative treatment with proximal GIC sealing, $20 \%$ regressed [31]. Again, the study failed to demonstrate that oral hygiene advice and motivation are effective to improve flossing uptake or an improvement in oral hygiene.

In contrast to this, another study [13] found the most varying results for the different assessment techniques: While the pair-wise visual comparison of the X-rays found only $47 \%$ of progression in the controls with non-operative measures within 18 months, this increased to $84 \%$ for the subtraction radiography.

On the other hand, also $43 \%$ of the sealed lesions progressed according to the subtraction radiography which is physically not very likely. The clearly higher progression rate in the Danish/ Colombian can possibly be explained with the higher caries activity in the group presenting moderate to high caries risk, while the first infiltration study employed dental students with much lower caries risk scores according to the Cariogram [32].

A "pragmatic" randomized trial in private dental practices in Germany found $31 \%$ of non-operatively treated lesions to progress after 18 months in high caries risk patients [33]. A South American study found a considerable reduction of 
caries risk over 3 years and a low progression rate of $18.5 \%$ over 3 years [34].

In conclusion, when managed non-operatively, initial proximal lesion progress at a rather slow velocity which seems to allow for a non-operative approach of the training in flossing and fluoride application. In high risk and younger patients, in molars and lesions extending to the EDJ or into dentin instead of enamel may show higher progression speed making microinvasive treatment more advisable.

\section{Micro-invasive treatment of proximal caries lesions}

For micro-invasive treatment options on proximal caries, five publications were included (Table 3 ). Four papers were systematic reviews and meta-analysis [35-38] and one study was a RCT [39], which was not included in the mentioned reviews.

The systematic review and meta-analysis by Ammari et al. [35] was based on ten studies (401 participants, split-mouth design), performed in primary and permanent dentition. From the included studies, seven were concluded studies [13, 30, $31,40-43$ ] and the others were ongoing studies with partial $[44,45]$ or follow-up results [46] of already published studies $[14,47]$. Four of the studies were selected for a meta-analysis due to their low risk of bias. Ammari et al. [35] concluded from their results that the technique of sealing non-cavitated proximal caries seemed to be effective in controlling proximal caries in the short and medium term (up to 36-month followup), compared with placebo treatments or with non-operative treatment options such as flossing instruction, or use of fluoride gel/varnish (see above).

A Cochrane systematic review and meta-analysis by Dorri et al. [36] was published based on eight trials (365 participants, split-mouth design). Six of the studies evaluated the effects of micro-invasive treatments in the permanent dentition $[12,13,31,40,43,47]$. The authors of this review [36] judged seven of the studies to be at high overall risk of bias, primarily due to lack of blinding of participants and personnel. The caries risk of the patients in the included studies ranged from low to high or was unknown. The available evidence showed that microinvasive treatment of proximal caries lesions arrests noncavitated enamel and initial dentinal lesions (limited to outer third of dentine, based on radiograph) and is significantly more effective than non-operative professional treatment (e.g. fluoride varnish) or advice (e.g. to floss). Nevertheless, due to the small number of studies, it remained unclear which micro-invasive technique offered the greatest benefit, or whether the effects of microinvasive treatment confer greater or lesser benefit according to different clinical or patient considerations.

The systematic review and meta-analysis by Krois et al. [37] included 15 split-mouth studies. Of these studies, six were the same as in the publication by Dorri et al.
[36]. The caries risk of the patients in the included studies ranged from moderate to high or was not stated. One study compared infiltration vs sealing and found no significant difference [43]. The other studies compared the efficacy of sealing/infiltration over non-invasive treatment [12-14, 30, 31, 33-35, 40, 41, 47-50]. For a mixed analysis in primary and permanent teeth, firm evidence on the superior efficacy of either sealing or infiltration over nonoperative treatment was reached. It was concluded that sealing or infiltration was likely to be more efficacious for arresting early (non-cavitated) proximal lesions than non-operative treatment [37]. The certainty of the evidence was graded as moderate. For the decision between sealing and infiltration, the authors recommended that to be guided by practical concerns beyond efficacy. It must be noted that some of the included studies were performed in primary teeth only, where most of the participants were classified as being at moderate to high risk of caries development and progression in primary teeth $[30,35,41$, 48]. Sub-analyses for primary and permanent teeth separately were not performed.

Another systematic review and meta-analysis [38] aimed to evaluate the caries-arresting effect of microinvasive interventions for non-cavitated proximal caries for lesions of different depths. The authors included randomized clinical trials. In total, eight papers were included. All these studies were included in the publication by Krois et al. [37] as well. The subgroup analysis showed that resin infiltration and resin sealant, but not glass ionomer cement (GIC), reduce the lesion progression compared with the control (no treatment or placebo, fluoride gel or fluoride varnish). It is important to note that the use of GIC was reported in one study only [31], and while this study showed a beneficial effect of GIC, it was likely under-powered to demonstrate this with statistical significance.

Liang et al. [38] found that both sealing and resin infiltration arrest enamel lesions and those around the EDJ, while only infiltration was effective for lesions involving the dentin. Liang et al. [38] concluded that resin infiltration is effective in arresting the progression of non-cavitated proximal caries involved in EDJ, while the therapeutic effects of resin sealant for different caries depths still need to be further confirmed. The authors suggest that dentists should carefully select appropriate micro-invasive interventions according to the different depths of non-cavitated proximal caries.

A recently published randomized controlled clinical trial [39], not included in any of these reviews, demonstrated that resin infiltration was superior over non-operative standard-ofcare including repeated professional F-varnish applications alone. The study was performed in a high caries risk population (cadet-candidates and cadets), and hence, the results cannot be generalized. 


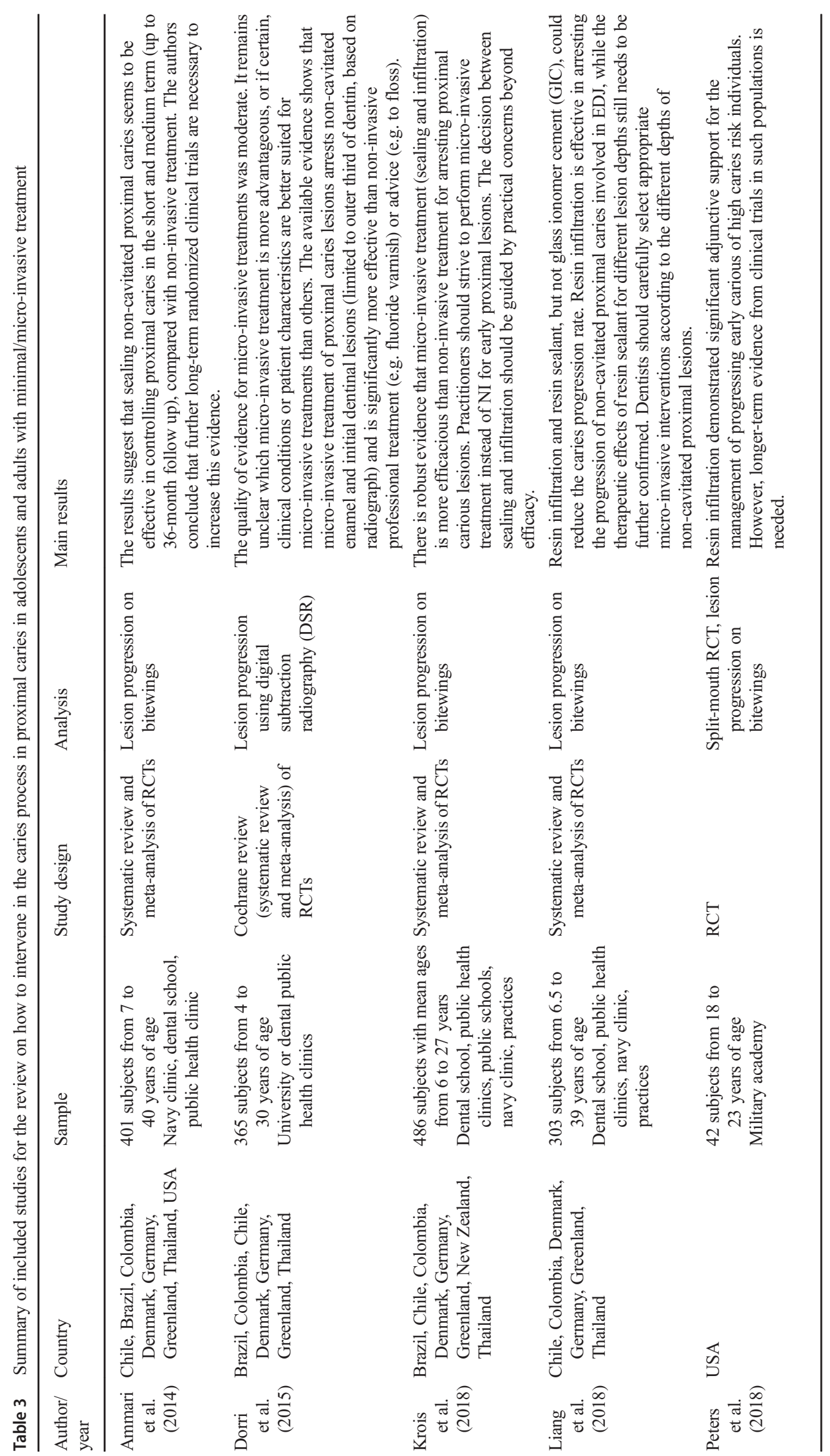




\section{Study outcome results and assessment of heterogeneity}

The studies on the "natural" progression of initial proximal lesion under the standard non-operative caries managements such as tooth brushing with fluoridated toothpaste additional fluoride use and partially recommendations for flossing showed a mostly low progression rates and velocities in adolescents and young adults. These studies were predominantly performed in countries with advanced preventive systems such as the USA, Sweden or Australia which had experienced a general caries decline. Even under these conditions, the prevalence of proximal initial caries lesions was high [17].

The progression rate decreased clearly with age or fluoride exposure, while it increased with caries activity or risk. It was higher for lesions at the EDJ compared with solely enamel lesions and for molars than for premolars.

Even in studies on proximal caries, the willingness in participants to improve their oral self-care was very low if flossing was recommended, resulting mostly in unchanged caries risk scores, persistent low self-reporting of flossing as well as considerable plaque and gingivitis scores around the lesion. Micro-invasive treatment was effective at a moderate level of evidence. The heterogeneity of the study samples and evaluation methods was moderate, but the trends were very similar in all studies (Supplemental Table $1 \& 2$ ).

\section{Restorative treatment of proximal caries lesions}

The search for systematic reviews with and without metaanalysis resulted in 103 publications (Fig. 1); out of which, 33 were selected for full text reading. Hand-searching of the reference lists revealed 6 publications that were checked for suitability. Totally, 39 publications were read in full text. Thirty-four systematic reviews were excluded, the most reviews as they were based not only on RCTs, but included also clinical trials and/or cohort studies. Finally, five systematic reviews were included in this meta-review (Supplemental Table 3). However, as these systematic reviews were based on RCTs on class I/II or load-bearing restorations in general, data on class II restorations were extracted from the original publications, if possible (Supplemental Table 4). Otherwise, these RCTs were removed.

The second search for more recent RCTs revealed 148 publications (Fig. 1); out of which, 27 were selected for full text reading. After removing publication duplicates and publications that did not meet the inclusion criteria, thirteen additional RCTs were included in this review.

Supplemental Table 3 shows the survival, AFRs and (sample-size weighted) mAFRs of posterior restorations based on the included systematic reviews. Supplemental Table 4 shows AFRs of class II restorations that were extracted from the respective RCTs.

The systematic review by Fron Chabouis et al. [51] compared ceramic and indirect composite restorations. Two studies were included, both on class II restorations. The 3-year overall failure risk was not significantly different among the materials.

The meta-analysis by Rasines Alcaraz et al. [15] on composite vs amalgam fillings for restoration of posterior permanent teeth was based on seven studies (Supplemental Table 3), but only one RCT allowed for extraction of class II restorations (Supplemental Table 4). The meta-analysis revealed that composite restorations had a significantly higher risk of failure compared with amalgam fillings. The only study that allowed for extraction of class II data was performed in children aged 8-12 years and reported a mAFR of $1.5 \%$ (amalgam) and $3.6 \%$ (composite) after 7 years (Supplemental Table 4).

The systematic review and meta-analysis by da Veiga et al. [52] analysed the longevity of direct and indirect resin composite restorations in permanent posterior teeth and found no significant difference (Supplemental Table 3). Only two studies allowed for extraction of class II restorations and found a mean mAFR of $1.8 \pm 0.4$ (direct composite) and $2.9 \pm 1.8$ (indirect composite) (Supplemental Table 4).

Schwendicke et al. [53] performed a network metaanalysis on directly placed load-bearing restorations based on 28 RCTs (Supplemental Table 3). The authors concluded that conventional and bulk-fill composites are most suitable for load-bearing posterior restorations. Also, when considering publications on class II restorations only $(n=14$, Supplemental Table 4), sample-size-weighted mAFRs were lower for bulk-fill composites (1.1\%) and conventional composites $(1.5 \%)$ than for ormocers $(2.3 \%)$ and siloranes $(3.2 \%)$ restorations. 2

The meta-analysis by Kruly et al. [54] was based on 14 studies and compared conventional composites with bulk-fill composites, silorane or ormocer restorations. Failure rates between the conventional composite and the tested materials were not significantly different (Supplemental Table 3 ). Considering data on class II restorations ( $n=7$, Supplemental Table 4), sample-size-weighted mAFRs amounted to $0.9 \%$ (bulk-fill composite), $2.0 \%$ (conventional composite), $2.5 \%$ (silorane) and $3.2 \%$ (ormocers).

In Supplemental Table 5, study characteristics of additional RCTs on class II restorations as well as survival and AFRs, and (sample-size weighted) mAFRs of the restorative materials, are displayed. The follow-up period of the included RCTs ranged from 3 to 30 years.

Table 4 summarizes survival, AFRs and (sample-size weighted) mAFRs of class II restorations (both extracted from systematic reviews and found by search for additional RCTs) of various materials. Bulk-fill composite exhibited lowest sample-size-weighted mAFRs and ceramic highest. 
Table 4 Annual failure rates of different restorative materials in class II restorations based on RCTs found in included systematic reviews and additional RCTs

\begin{tabular}{|c|c|c|c|c|c|c|c|c|}
\hline Material & $N$ & $n$ & $\begin{array}{l}\text { Follow-up time of } \\
\text { included studies (years) }\end{array}$ & $\begin{array}{l}n \\
\text { failure }\end{array}$ & $\begin{array}{l}\text { Survival } \\
\text { proportion } \pm \mathrm{SD} \\
(\%)\end{array}$ & $\begin{array}{l}\mathrm{AFR} \pm \\
\mathrm{SD}\end{array}$ & $\begin{array}{l}\mathrm{mAFR} \\
\pm \mathrm{SD}\end{array}$ & $\begin{array}{l}\text { Sample-size- } \\
\text { weighted mAFR }\end{array}$ \\
\hline Amalgam & $1[5]$ & 427 & 7 & 43 & 89.9 & 1.4 & 1.5 & 1.5 \\
\hline Bulk-fill composite & $\begin{array}{l}9[11,13,18,19,21,31, \\
36-38]\end{array}$ & 386 & $2-10$ & 20 & $94.8 \pm 7.7$ & $1.1 \pm 0.9$ & $1.1 \pm 1.0$ & 1.2 \\
\hline $\begin{array}{l}\text { Chemical-cured } \\
\text { composite }\end{array}$ & $2[28,29]$ & 83 & $27-30$ & 31 & $62.7 \pm 0.3$ & $1.3 \pm 0.1$ & $1.6 \pm 0.1$ & 1.6 \\
\hline $\begin{array}{l}\text { Conventional } \\
\text { composite }\end{array}$ & $\begin{array}{c}21[5,7,8,10-12,14-16, \\
24-29,32-35,37,38]\end{array}$ & 1481 & $1-30$ & 210 & $85.8 \pm 12.1$ & $1.4 \pm 1.4$ & $1.5 \pm 1.5$ & 2.2 \\
\hline $\begin{array}{l}\text { Glass ionomer-based } \\
\text { restoration system }\end{array}$ & $1[26]$ & 25 & 4 & 2 & 92.0 & 2.0 & 2.1 & 2.1 \\
\hline Indirect composite & $2[7,8]$ & 158 & $5-11$ & 28 & $82.3 \pm 2.1$ & $2.7 \pm 1.7$ & $2.9 \pm 1.8$ & 2.9 \\
\hline Ormocer & $\begin{array}{l}9[10,12,13,19-22,31, \\
\quad 36]\end{array}$ & 515 & $2-8$ & 56 & $89.1 \pm 7.3$ & $2.1 \pm 1.3$ & $2.3 \pm 1.5$ & 2.2 \\
\hline Silorane & $5[15,18,20,24,25]$ & 249 & $1-10$ & 17 & $93.2 \pm 5.0$ & $2.4 \pm 2.2$ & $2.5 \pm 2.2$ & 2.5 \\
\hline Ceramic & $3[2,3,30]$ & 112 & $3-10$ & 26 & $76.8 \pm 16.8$ & $3.0 \pm 2.0$ & $3.5 \pm 2.4$ & 3.8 \\
\hline
\end{tabular}

$N$ number of included RCTs, $n$ number of followed restorations, $A F R$ annual failure rate, $S D$ standard deviation, $m A F R$ mean annual failure rate according to $m A F R=1-\sqrt[z]{1-x}$ ( $x$, failure rate; $z$, number of observation years). In case of multiple reports of the same study, only the source with the longest follow-up was considered to avoid overlapping data

Based on this table, risk of failure between composite (control) and different restorative materials was compared by pairwise random-effects meta-analyses (Fig. 2). Composite showed a significantly higher risk of failure than amalgam (mean risk ratio $2.247 ; p<0.001$ ). All other materials performed not significantly different than conventional composite. Studies focussing on the comparison between conventional composites and chemical-cured composites showed moderate heterogeneity $\left(I^{2}=55.8 \%\right)$. Furthermore, an asymmetric funnel plot and Egger's regression intercept test indicate possible publication bias $(p=0.004$; Supplemental Figure 2).

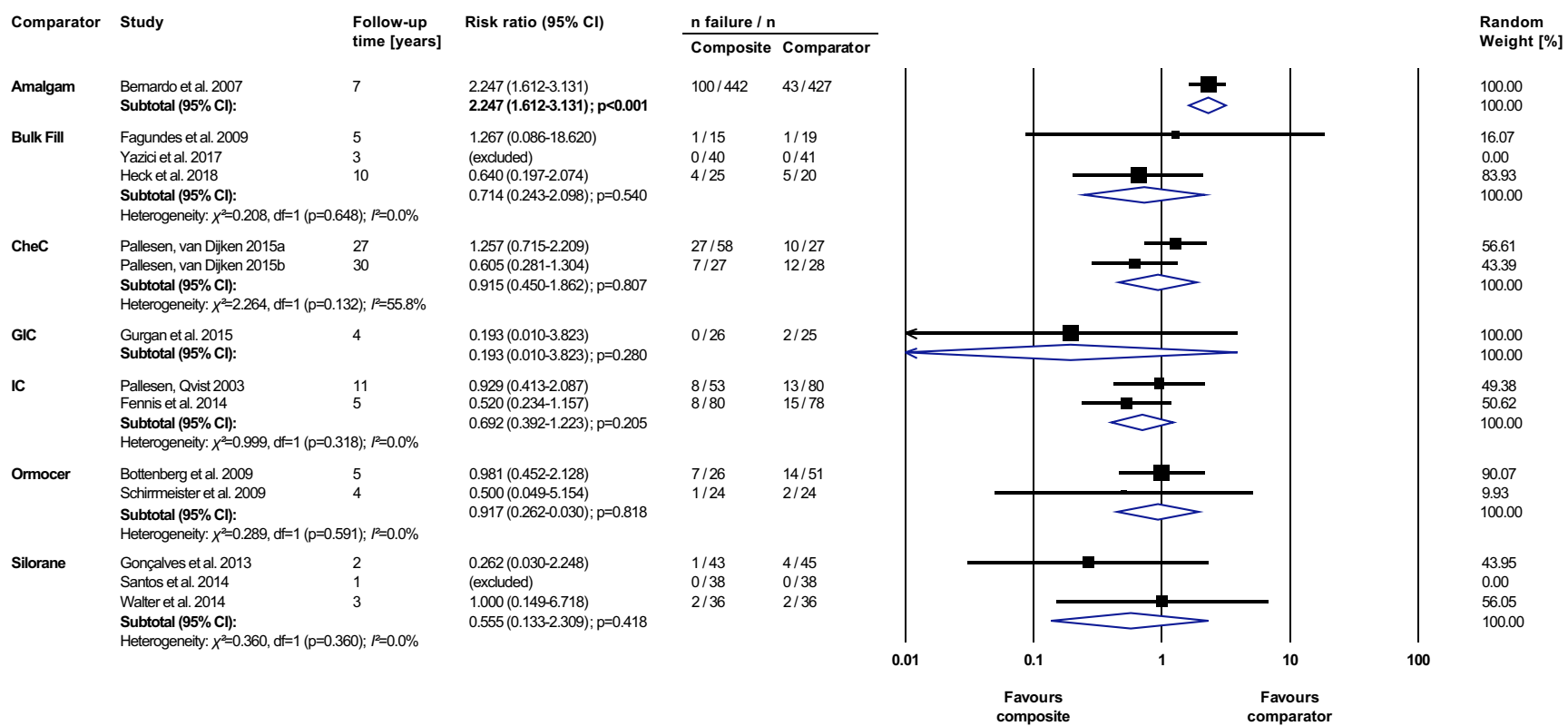

Fig. 2 Forest plots of pairwise comparison of the risk of failure between different materials (comparators) and composite in class II restorations. Risk ratio and $95 \%$ confidence interval $(95 \% \mathrm{CI})$ of risk of failure among different restorative materials (comparators) vs the control (composite) are shown. Risk ratio $<1$ indicates increased risk of failure compared with composite. Diamonds indicate pooled effect estimates. Studies without failures (100\% survival in both groups) could not be included in metaanalysis. CheC, chemical-cured composite; GIC, glass ionomer based restoration system; IC, indirect composite 
Overall, considerable heterogeneity was observed in the five included systematic reviews with respect to restorative materials under analysis, the subject characteristics, and outcome measures. Furthermore, quality assessment scales and reporting of effect scores varied among the publications.

\section{Quality assessment and grading the "body of evidence"}

Estimation of the risk of bias related to the reporting and methodological quality of the included primary publications is presented in Supplemental Tables 1-2,6 and Supplemental Fig. 1. Due to the nature of mostly longitudinal cohort studies in non-operative interventions and resulting limitations, this systematic review indicates that there is low evidence to support nonoperative management of proximal caries lesion (Supplemental Table 1).

The more recent RCT on micro-invasive techniques and the resulting systematic reviews (Supplemental Table 2) were of considerably better quality and present with a low estimated potential risk of bias. For micro-invasive treatment, there is moderate evidence of superiority over non-operative care, especially in high caries groups or lesions in molars or extending into dentin.

Regarding restorative care in cavitated proximal lesions, many studies did not report on allocation concealment leading to unclear risk of bias in this domain. Blinding of patients and/ or personnel was either not reported, or it was stated that blinding was impossible due to different treatment strategies/ materials. However, in these cases, the review team found the information provided insufficient to judge whether the outcome was likely to be influenced by lack of blinding (Supplemental Figure 1, Supplemental Table 6). Thus, there was low evidence that conventional composites show a significantly higher risk of failure than amalgams. The 5 systematic reviews and 13 recent RCTs showed varying sample sizeweighted mean annual failure rates of class II restorations between 1.2 (bulk fill composite) and 3.8\% (ceramic) at a low level of evidence and the limitation of no direct comparative studies between these materials.

\section{Discussion}

The prevalence of proximal lesions in adolescents and young adults remains to be high, even in low risk populations [10]. However, these lesions progress at low proportions and velocity, at least in countries with established caries preventive systems which have experienced a considerable caries decline.

The slow progression of initial lesions allows for noninvasive treatment which ideally involves improved sitespecific oral home care and fluoride application.
Unfortunately, self-performed or unsupervised flossing does not seem to prevent proximal caries at least in adolescents, possibly because they do not comply. But even adults in clinical trials on proximal caries exhibit considerable and constant plaque and gingivitis around initial caries lesions, and they report a very low rate of flossing [13]. The theoretical potential of flossing could be higher as supervised, and professional flossing clearly prevents the initiation of new proximal lesions [55]. Fluorides are clearly beneficial for initial proximal lesions, as they are for the general caries process [29], and this approach was already employed in the 1970s and 1980s [25]. But even then, the poor compliance with instructions to floss regularly was detected [56].

This systematic review found several indications that the progression of proximal caries is very closely associated with the individual caries risk or activity which is also biologically plausible. Thus, it seems reasonable to restrict minimally invasive approaches to cases where non-operative caries control of initial proximal lesions has failed over time or a high caries risk cannot be reduced.

The superiority of sealants or infiltrations has been shown, although the systematic reviews and meta-analysis for microinvasive approach on proximal surfaces included both primary and permanent teeth, mainly without sub-group analysis. Hence, the outcome and recommendations cannot be transferred to permanent dentition only and should be interpreted with care. Especially in primary molars, lesion progression is faster than in permanent molars [25] leading to an overestimation of the effect in permanent teeth or adults. Here, Mejare et al. [9] found consistently decreasing proximal caries progression with age. In addition, the individual caries risk was not taken into account for the analyses. Subjects with caries lesions were recruited in the studies representing per se a moderate to high caries activity. When this was lowered, the progression was minimal [34], while persisting high caries activity resulted in higher progression rates [13].

Almost all studies included resin sealants and resin infiltration only which does not allow sub-group analyses for the different techniques. Especially, the only study on proximal application of glass ionomer cement does not allow for a final judgement. Still, the aspects that GICs release fluoride of and proximal caries activity decreases with age give biological plausibility to this approach applying a "temporary" proximal sealant for the time at risk [31].

With regard to lesion progression which is detected radiographically, the technique of sealing or resin infiltration of non-cavitated was effective in controlling proximal caries. The overall quality of evidence for micro-invasive treatments was moderate, and a potential publication and funding bias cannot be excluded. It also remains unclear which microinvasive treatment is more advantageous. Factors which vary in different studies are patient's caries activity status and depth of the non-cavitated lesion (i.e. in enamel or beyond the EDJ) 
and the duration of follow-up controls. These variables should be taken into account for further studies and be standardized as much as possible.

When cavitation of proximal lesion has occurred in the permanent dentition or lesions have progressed well into dentine, non- or minimally invasive approaches do not seem to be useful options, and a restorative technique should be employed. Class II restorations last long in RCTs with sample size-weighted mAFRs varying between 1.2 and $3.8 \%$ (Table 4). However, the meta-analysis of different restorative materials used for class II restorations comes along with some limitations: (1) RCTs on specific restorative materials for class II, e.g. amalgam and glass ionomer cement, are very limited, thus the risk of bias is increased. Only one 4-year RCT was included in this review comparing a glass ionomer based restoration system with a conventional composite [57]. Also, only one RCT comparing amalgam and composite in class II restorations was available [58], and no further RCT including more recently developed composite materials, e.g. bulk-fill composites, could be identified in the additional search. Also, the most recent RCT included in the systematic review by Rasines Alcaraz et al. [15] comparing posterior composite and amalgam restorations (class I and II) was published in 2007. Thus, the higher survival of amalgam compared with composite found in the RCT for class II [58] and also in the systematic review by Rasines Alcaraz et al. (for class I and II) [15] gives low-quality evidence to suggest that resin composites lead to a higher risk of secondary caries and potentially higher failure rates than amalgam. The benefits of amalgam are particularly important for countries where amalgam is still the material of choice for posterior restorations despite the global phase down of dental mercury use. Besides, some of the RCTs reported on restorative materials that are no longer available, which also limits the validity of this meta-review. (2) Survival of restorations depends on various patient-related risk factors [59-61] which were not addressed in this meta-review. Only about a quarter of the RCTs assessed the caries risk of the patients as, e.g. [62-64], showing more failures due to secondary caries in the high-risk groups. Few studies indicated that the type of restorative material might also affect the development of secondary caries, as caries as reason for failure was more frequently observed in composite than in amalgam restorations [58], especially in high-risk patients [24]. However, more recent systematic reviews demonstrated that not only caries risk, but various patient-related factors might affect survival of the restoration [60,61]. (3) Most RCTs included not only class II restorations placed due to primary caries, but also replacement restorations of failed fillings, which are probably larger and more likely to fail (again) than newly placed restorations. A recent study [59] also showed that restorations placed due to caries were less prone to fail than restorations placed due to fracture. In view of this, survival of class II restorations for cavitated proximal caries lesions might be even slightly better than demonstrated in the present review.

\section{Further research}

The benefit of non- and micro-invasive treatment options for initial proximal caries lesion should be assessed in clinical studies with respect to the participants' caries risk or activity and their compliance with reducing it. Also cost benefit analyses are needed for a comprehensive evaluation of the different treatment approaches in order to gain information on their efficiency rather than efficacy. Regarding the improved composite materials, their long-term effectiveness for proximal restorations should be evaluated. The emerging evidence should finally lead to an evidence and expert-based decision tree supporting dental practitioners in decision taking on how and when to intervene in proximal caries.

\section{Conclusion}

Proximal caries lesions can be managed successfully with non-operative/invasive, minimal/micro-invasive and restorative treatment depending on lesion stage and caries activity. Non-operative care should be employed mainly in adults and on enamel lesions, while micro-invasive treatment is especially suited for higher caries risk patients like adolescents and lesions extending to the EDJ or dentin. In cavitated proximal lesions, restorative treatment should be performed. Even in these cases, non-operative care for the reduction of the overall caries activity should be performed as restorations potentially fail due to secondary caries.

Funding Information Open Access funding provided by Projekt DEAL.

\section{Compliance with ethical standards}

Conflict of interest The authors declare that they have no conflict of interest.

Ethical approval For this systematic review, no ethical approval was needed.

Informed consent For this systematic review, no informed consent was needed.

Open Access This article is licensed under a Creative Commons Attribution 4.0 International License, which permits use, sharing, adaptation, distribution and reproduction in any medium or format, as long as you give appropriate credit to the original author(s) and the source, provide a link to the Creative Commons licence, and indicate if changes were made. The images or other third party material in this article are included in the article's Creative Commons licence, unless indicated 
otherwise in a credit line to the material. If material is not included in the article's Creative Commons licence and your intended use is not permitted by statutory regulation or exceeds the permitted use, you will need to obtain permission directly from the copyright holder. To view a copy of this licence, visit http://creativecommons.org/licenses/by/4.0/.

\section{References}

1. Kassebaum NJ, Bernabé E, Dahiya M, Bhandari B, Murray CJ, Marcenes W (2015) Global burden of untreated caries: a systematic review and metaregression. J Dent Res 94(5):650-658. https://doi. org/10.1177/0022034515573272

2. Kassebaum NJ, Smith AGC, Bernabé E, Fleming TD, Reynolds AE, Vos T, Murray CJL, Marcenes W, GBD 2015 Oral Health Collaborators (2017) Global, regional, and national prevalence, incidence, and disability-adjusted life years for oral conditions for 195 countries, 1990-2015: a systematic analysis for the global burden of diseases, injuries, and risk factors. J Dent Res 96(4):380 387. https://doi.org/10.1177/0022034517693566

3. Marcenes W, Kassebaum NJ, Bernabé E et al (2013) Global burden of oral conditions in 1990-2010: a systematic analysis. J Dent Res 92(7):592-597. https://doi.org/10.1177/0022034513490168

4. IDZ (2016) Fünfte Deutsche Mundgesundheitsstudie - DMS V, Köln

5. DPHEP (2018) National Dental Epidemiology Programme for England: oral health survey of five-year-old children 2017. Public Health England, London

6. Team DAJ (2017) Epidemiologische Begleituntersuchungen zur Gruppenprophylaxe 2016. Deutsche Arb.-Gemeinsch. f. Jugendzahnpflege, Bonn

7. Mejàre I, Källestål C, Stenlund H, Johansson H (1998) Caries development from 11 to 22 years of age: a prospective radiographic study. Prevalence and distribution. Caries Res 32(1):10-16. https:// doi.org/10.1159/000016424

8. Gröndahl HG, Andersson B, Torstensson T (1984) Caries increment and progression in teenagers when using a prevention- rather than restoration-oriented treatment strategy. Swed Dent J 8(5):237242

9. Mejàre I, Stenlund H, Zelezny-Holmlund C (2004) Caries incidence and lesion progression from adolescence to young adulthood: a prospective 15-year cohort study in Sweden. Caries Res 38(2): 130-141. https://doi.org/10.1159/000075937

10. Schwendicke F, Splieth C, Breschi L, Banerjee A, Fontana M, Paris S, Burrow MF, Crombie F, Page LF, Gatón-Hernández P, Giacaman R, Gugnani N, Hickel R, Jordan RA, Leal S, Lo E, Tassery H, Thomson WM, Manton DJ (2019) When to intervene in the caries process? An expert Delphi consensus statement. Clin Oral Investig 23(10):3691-3703. https://doi.org/10.1007/s00784-019-03058-w

11. Machiulskiene V, Campus G, Carvalho JC et al (2019) Terminology of dental caries and dental caries management: consensus report of a workshop organized by ORCA and cariology research group of IADR. Caries Res 1-8. https://doi.org/10.1159/000503309

12. Alkilzy M, Berndt C, Splieth CH (2011) Sealing proximal surfaces with polyurethane tape: three-year evaluation. Clin Oral Investig 15(6):879-884. https://doi.org/10.1007/s00784-010-0457-z

13. Martignon S, Ekstrand KR, Ellwood R (2006) Efficacy of sealing proximal early active lesions: an 18-month clinical study evaluated by conventional and subtraction radiography. Caries Res 40(5): 382-388. https://doi.org/10.1159/000094282

14. Meyer-Lueckel H, Bitter K, Paris S (2012) Randomized controlled clinical trial on proximal caries infiltration: three-year follow-up. Caries Res 46(6):544-548. https://doi.org/10.1159/000341807

15. Rasines Alcaraz MG, Veitz-Keenan A, Sahrmann P et al (2014) Direct composite resin fillings versus amalgam fillings for permanent or adult posterior teeth. Cochrane Database Syst Rev 3:CD005620. https://doi.org/10.1002/14651858.CD005620.pub2

16. Söderholm KJ, Tyas MJ, Jokstad A (1998) Determinants of quality in operative dentistry. Crit Rev Oral Biol Med 9(4):464-479. https://doi.org/10.1177/10454411980090040501

17. Jacobsen ID, Crossner C-G, Eriksen HM, Espelid I, Ullbro C (2019) Need of non-operative caries treatment in 16-year-olds from northern Norway. Eur Arch Paediatr Dent 20(2):73-78. https://doi. org/10.1007/s40368-018-0387-z

18. Higgins JPT, Thompson SG (2002) Quantifying heterogeneity in a meta-analysis. Stat Med 21(11):1539-1558. https://doi.org/10. 1002/sim. 1186

19. Egger M, Davey Smith G, Schneider M, Minder C (1997) Bias in meta-analysis detected by a simple, graphical test. BMJ 315(7109): 629-634. https://doi.org/10.1136/bmj.315.7109.629

20. Moher D, Liberati A, Tetzlaff J et al (2009) Preferred reporting items for systematic reviews and meta-analyses: the PRISMA statement. J Clin Epidemiol 62(10):1006-1012. https://doi.org/10.1016/ j.jclinepi.2009.06.005

21. Shea BJ, Reeves BC, Wells G, Thuku M, Hamel C, Moran J, Moher D, Tugwell P, Welch V, Kristjansson E, Henry DA (2017) AMSTAR 2: a critical appraisal tool for systematic reviews that include randomised or non-randomised studies of healthcare interventions, or both. BMJ 358:j4008. https://doi.org/10.1136/bmj. j4008

22. Higgins J, Green S (2011) cochrane handbook for systematic reviews of interventions version 5.1.0. http://handbook.cochrane.org

23. Wells G, Shea B, O'Connell D et al. (2016) The Newcastle-Ottawa Scale (NOS) for assessing the quality of nonrandomized studies in meta-analysis http://www.ohri.ca/programs/clinical_epidemiology/ oxford.asp

24. Opdam NJM, Bronkhorst EM, Loomans BAC et al (2010) 12-year survival of composite vs. amalgam restorations. J Dent Res 89(10): 1063-1067. https://doi.org/10.1177/0022034510376071

25. Shwartz M, Gröndahl HG, Pliskin JS, Boffa J (1984) A longitudinal analysis from bite-wing radiographs of the rate of progression of approximal carious lesions through human dental enamel. Arch Oral Biol 29(7):529-536. https://doi.org/10.1016/0003-9969(84) 90074-8

26. Pitts NB (1984) Systems for grading approximal carious lesions and overlaps diagnosed from bitewing radiographs. Proposals for future standardization. Community Dent Oral Epidemiol 12(2):114-122. https://doi.org/10.1111/j.1600-0528.1984.tb01423.x

27. Vanderas AP, Skamnakis J (2003) Effectiveness of preventive treatment on approximal caries progression in posterior primary and permanent teeth: a review. Eur J Paediatr Dent 4(1):9-15

28. Granath L, Kahlmeter A, Matsson L, Schröder U (1980) Progression of proximal enamel caries in early teens related to caries activity. Acta Odontol Scand 38(4):247-251. https://doi. org/10.3109/00016358009003497

29. Arrow P (2007) Incidence and progression of approximal carious lesions among school children in Western Australia. Aust Dent J 52(3):216-226. https://doi.org/10.1111/j.1834-7819.2007.tb00492. $\mathrm{x}$

30. Martignon S, Chavarría N, Ekstrand KR (2010) Caries status and proximal lesion behaviour during a 6-year period in young adult Danes: an epidemiological investigation. Clin Oral Investig 14(4): 383-390. https://doi.org/10.1007/s00784-009-0306-0

31. Trairatvorakul C, Itsaraviriyakul S, Wiboonchan W (2011) Effect of glass-ionomer cement on the progression of proximal caries. J Dent Res 90(1):99-103. https://doi.org/10.1177/0022034510381265

32. Petersson GH (2003) Assessing caries risk-using the Cariogram model. Swed Dent J Suppl (158): 1-65

33. Meyer-Lueckel H, Balbach A, Schikowsky C, Bitter K, Paris S (2016) Pragmatic RCT on the efficacy of proximal caries infiltration. J Dent Res 95(5):531-536. https://doi.org/10.1177/ 0022034516629116 
34. Arthur RA, Zenkner JE, d'Ornellas Pereira Júnior JC, Correia RT, Alves LS, Maltz M (2018) Proximal carious lesions infiltration-a 3year follow-up study of a randomized controlled clinical trial. Clin Oral Investig 22(1):469-474. https://doi.org/10.1007/s00784-0172135-x

35. Ammari MM, Soviero VM, da Silva Fidalgo TK, Lenzi M, Ferreira DM, Mattos CT, de Souza IP, Maia LC (2014) Is non-cavitated proximal lesion sealing an effective method for caries control in primary and permanent teeth? A systematic review and meta-analysis. J Dent 42(10):1217-1227. https://doi.org/10.1016/j.jdent. 2014.07.015

36. Dorri M, Dunne SM, Walsh T et al (2015) Micro-invasive interventions for managing proximal dental decay in primary and permanent teeth. Cochrane Database Syst Rev 11:CD010431. https://doi.org/ 10.1002/14651858.CD010431.pub2

37. Krois J, Göstemeyer G, Reda S, Schwendicke F (2018) Sealing or infiltrating proximal carious lesions. J Dent 74:15-22. https://doi. org/10.1016/j.jdent.2018.04.026

38. Liang Y, Deng Z, Dai X, Tian J, Zhao W (2018) Micro-invasive interventions for managing non-cavitated proximal caries of different depths: a systematic review and meta-analysis. Clin Oral Investig 22(8):2675-2684. https://doi.org/10.1007/s00784-0182605-9

39. Peters MC, Hopkins AR, Yu Q (2018) Resin infiltration: an effective adjunct strategy for managing high caries risk-a within-person randomized controlled clinical trial. J Dent 79:24-30. https://doi. org/10.1016/j.jdent.2018.09.005

40. Gomez SS, Basili CP, Emilson C-G (2005) A 2-year clinical evaluation of sealed noncavitated approximal posterior carious lesions in adolescents. Clin Oral Investig 9(4):239-243. https://doi.org/10. 1007/s00784-005-0010-7

41. Ekstrand KR, Bakhshandeh A, Martignon S (2010) Treatment of proximal superficial caries lesions on primary molar teeth with resin infiltration and fluoride varnish versus fluoride varnish only: efficacy after 1 year. Caries Res 44(1):41-46. https://doi.org/10.1159/ 000275573

42. Abuchaim C, Rotta M, Grande RHM, Loguercio AD, Reis A (2010) Effectiveness of sealing active proximal caries lesions with an adhesive system: 1-year clinical evaluation. Braz Oral Res 24(3): 361-367. https://doi.org/10.1590/s1806-83242010000300017

43. Martignon S, Ekstrand KR, Gomez J, Lara JS, Cortes A (2012) Infiltrating/sealing proximal caries lesions: a 3-year randomized clinical trial. J Dent Res 91(3):288-292. https://doi.org/10.1177/ 0022034511435328

44. Peters M, Tuzzio F, Nedley M et al (2013) Resin infiltration effects in a caries-active environment. J Dent Res 92:377

45. Correa RT (2012) Selamento de lesões de cárie proximal com infiltrante resinoso: estudo clínico randomizado. Departamento d'Odontologia Preventiva e Social. Porto Alegre: Universidade Federal do Rio Grande do Sul. Dissertação (Mestrado em programa de pós graduação em odontologia): 44

46. Paris S, Bitter K, Meyer-Luckel H (2013) Five-year follow-up of a randomized clinical trial on the efficacy of proximal caries infiltration. [abstract]. Caries Res(47): 519

47. Paris S, Hopfenmuller W, Meyer-Lueckel H (2010) Resin infiltration of caries lesions: an efficacy randomized trial. J Dent Res 89(8):823-826. https://doi.org/10.1177/0022034510369289

48. Foster Page LA, Beckett D, Ahmadi R, Schwass DR, Leon de la Barra S, Moffat SM, Meldrum A, Thomson WM (2017) Resin infiltration of caries in primary molars in a community setting: 24-month randomized controlled trial findings. JDR Clin Trans Res 2(3):287-294. https://doi.org/10.1177/2380084417699400

49. Basili CP, Emilson CG, Corvalan GC, Moran MP, Torres C, Quiroz MD, Gomez SS (2017) Preventive and therapeutic proximal sealing: a 3.5-year randomized controlled clinical trial follow-up. Caries Res 51(4):387-393. https://doi.org/10.1159/000470851
50. Gomez SS, Emilson C-G, Corvalan GC, Quiroz MD, Moran MP (2014) Efficacy of sealing the mesial surfaces of first permanent molars with respect to the status of the distal surfaces of the second primary molars in children at high caries-risk. Eur Arch Paediatr Dent 15(2):65-73. https://doi.org/10.1007/s40368-013-0066-z

51. Fron Chabouis H, Smail Faugeron V, Attal J-P (2013) Clinical efficacy of composite versus ceramic inlays and onlays: a systematic review. Dent Mater 29(12):1209-1218. https://doi.org/10. 1016/j.dental.2013.09.009

52. da Veiga AMA, Cunha AC, Ferreira DMTP, da Silva Fidalgo TK, Chianca TK, Reis KR, Maia LC (2016) Longevity of direct and indirect resin composite restorations in permanent posterior teeth: a systematic review and meta-analysis. J Dent 54:1-12. https://doi. org/10.1016/j.jdent.2016.08.003

53. Schwendicke F, Göstemeyer G, Blunck U, Paris S, Hsu LY, Tu YK (2016) Directly placed restorative materials: review and network meta-analysis. J Dent Res 95(6):613-622. https://doi.org/10.1177/ 0022034516631285

54. Kruly PC, Giannini M, Pascotto RC, Tokubo LM, Suga USG, Marques ACR, Terada RSS (2018) Meta-analysis of the clinical behavior of posterior direct resin restorations: low polymerization shrinkage resin in comparison to methacrylate composite resin. PLoS One 13(2):e0191942. https://doi.org/10.1371/journal.pone. 0191942

55. Hujoel PP, Cunha-Cruz J, Banting DW, Loesche WJ (2006) Dental flossing and interproximal caries: a systematic review. J Dent Res 85(4):298-305. https://doi.org/10.1177/154405910608500404

56. Frandsen A (1985) Changing patterns of attitudes and oral health behaviour. Int Dent J 35(4):284-290

57. Gurgan S, Kutuk ZB, Ergin E, Oztas SS, Cakir FY (2015) Fouryear randomized clinical trial to evaluate the clinical performance of a glass ionomer restorative system. Oper Dent 40(2):134-143. https://doi.org/10.2341/13-239-C

58. Bernardo M, Luis H, Martin MD, Leroux BG, Rue T, Leitão J, DeRouen T (2007) Survival and reasons for failure of amalgam versus composite posterior restorations placed in a randomized clinical trial. J Am Dent Assoc 138(6):775-783. https://doi.org/10. 14219/jada.archive.2007.0265

59. Laske M, Opdam NJM, Bronkhorst EM, Braspenning JCC, Huysmans MCDNJM (2019) Risk factors for dental restoration survival: a practice-based study. J Dent Res 98(4):414-422. https://doi.org/10.1177/0022034519827566

60. van de Sande FH, Collares K, Correa MB et al (2016) Restoration survival: revisiting patients' risk factors through a systematic literature review. Oper Dent 41(S7):S7-S26. https://doi.org/10.2341/ 15-120-LIT

61. Opdam NJM, van de Sande FH, Bronkhorst E, Cenci MS, Bottenberg P, Pallesen U, Gaengler P, Lindberg A, Huysmans MC, van Dijken J (2014) Longevity of posterior composite restorations: a systematic review and meta-analysis. J Dent Res 93(10): 943-949. https://doi.org/10.1177/0022034514544217

62. van Dijken JWV, Pallesen U (2016) Posterior bulk-filled resin composite restorations: a 5-year randomized controlled clinical study. J Dent 51:29-35. https://doi.org/10.1016/j.jdent.2016.05.008

63. van Dijken JWV, Pallesen U (2017) Bulk-filled posterior resin restorations based on stress-decreasing resin technology: a randomized, controlled 6-year evaluation. Eur J Oral Sci 125(4):303-309. https://doi.org/10.1111/eos.12351

64. van Dijken JWV, Pallesen U (2017) Durability of a low shrinkage TEGDMA/HEMA-free resin composite system in class II restorations. A 6-year follow up. Dent Mater 33(8):944-953. https://doi. org/10.1016/j.dental.2017.04.021

Publisher's note Springer Nature remains neutral with regard to jurisdictional claims in published maps and institutional affiliations. 